\title{
Is the concept of "peanut-free schools" useful in the routine management of peanut-allergic children at risk of anaphylaxis?
}

\author{
Position paper of the Food Allergy Working Group of the German Society for \\ Allergology and Clinical Immunology (Deutsche Gesellschaft für Allergologie \\ und klinische Immunologie, DGAKI)
}

Imke Reese · Birgit Ahrens · Barbara Ballmer-Weber · Kirsten Beyer · Katharina Blümchen · Sabine Doelle-Birke • Annice Heratizadeh · Jörg Kleine-Tebbe · Lars Lange · Susanne Lau · Ute Lepp · Vera Mahler ·

Christiane Schäfer · Sabine Schnadt · Zsolt Szepfalusi · Anja Wassmann-Otto · Thomas Werfel · Margitta Worm

Received: 15 June 2020 / Accepted: 25 June 2020 / Published online: 1 September 2020

(C) The Author(s) 2020

\section{Summary \\ Background Parents of school-age children with food allergies and potential anaphylactic reactions want their children to have an unburdened and risk-free everyday school life. Thus, particularly in the case of}

\section{Dr. I. Reese}

Nutrition Counseling and Therapy with Special Focus on Allergology, Ansprengerstraße 19, 80803 Munich, Germany

Dr. B. Ahrens · Priv. Doz. Dr. K. Blümchen

Department of Pediatric and Adolescent Medicine,

Allergology, Pulmonology, and Cystic Fibrosis Unit,

University Hospital Frankfurt, Goethe University, Frankfurt am Main, Germany

Dr. B. Ahrens · Prof. Dr. V. Mahler

Clinical Allergology Section, Paul-Ehrlich Institute, Langen, Germany

Prof. Dr. B. Ballmer-Weber

Department of Dermatology, University Hospital Zurich, Zurich, Switzerland

Department of Dermatology and Allergology, Cantonal Hospital St. Gallen, St. Gallen, Switzerland

Prof. Dr. K. Beyer · Prof. Dr. S. Lau

Department of Pediatric Pulmonology, Immunology, and Intensive Care Medicine, Charité-University Hospital Berlin, Berlin, Germany

Dr. S. Doelle-Birke · Prof. Dr. M. Worm $(\bowtie)$ Department of Dermatology, Venereology, and Allergology, Charité-University Hospital Berlin, Charitéplatz 1, 10117 Berlin, Germany margitta.worm@charite.de peanut allergy, demands for peanut-free schools are put forward.

Results and discussion The position paper of the food allergy working group of the German Society for Allergology and Clinical Immunology (Deutsche

Dr. A. Heratizadeh • Prof. Dr. T. Werfel

Immunodermatology and Experimental Allergology Unit, Department of Dermatology, Allergology, and Venereology, Medical University Hannover, Hannover, Germany

Prof. Dr. J. Kleine-Tebbe

Westend Allergy and Asthma Center, Berlin, Germany

Dr. L. Lange

St. Marien Hospital, Bonn, Germany

Dr. U. Lepp

Pulmonary Medicine, Allergology, Dr. Lepp Practice, Buxtehude, Germany

C. Schäfer

Nutritional Therapy, Schwarzenbek, Germany

S. Schnadt

German Allergy and Asthma Association (DAAB),

Mönchengladbach, Germany

Prof. Dr. Z. Szepfalusi

Department of Pediatrics and Adolescent Medicine, Medical University Vienna, Vienna, Austria

Dr. A. Wassmann-Otto

Dermatological Outpatient Clinic, Hamburg, Germany 
Gesellschaft für Allergologie und klinische Immunologie) highlights why the concept of peanut-free schools does not protect peanut allergic children, but rather bears potential disadvantages and risks for all those involved. The focus on peanut as a potential trigger of anaphylactic reactions ignores other relevant triggers. Conclusion In order to address the fears and concerns of patients, parents, and school staff, it is mandatory to develop various coping strategies. These should enable and ensure the safety and participation of food-allergic pupils in classes and other school activities. Therefore, it is important to implement adequate measures for allergen avoidance and emergency treatment for students with confirmed food allergies.

Keywords Peanut allergy · Food allergy $\cdot$ Coping strategies · Allergen avoidance $\cdot$ Emergency treatment

\section{Introduction}

The call for "peanut-free schools" is based on the idea of enabling school-age children with peanut allergy and either previous anaphylactic reactions or a high risk of experiencing such a reaction to enjoy an unburdened and risk-free school life. The following article critically discusses the concept of "peanut-free schools" taking into account the risks and disadvantages, experience with concepts of this kind, as well as data on eliciting doses in order to definitively arrive at useful recommendations for dealing with (peanut)allergic children in the school setting.

\section{Educational disadvantage due to limited choice of schools}

This type of concept is associated with enormous expectations on the part of parents of affected children and creates the impression that schools without this designation are "unprotected places". As such, the supposed protection offered by attending a "peanutfree school" can have a major influence on the choice of school and result in an educational disadvantage for the allergic child; however, an allergic child should also have the freedom to choose a school according to his or her abilities (musical, bilingual, teaching focus, etc.). If the label "peanut-free school" is the deciding factor in the choice of school, a child may be disadvantaged in terms of his or her interests and abilities.

\section{Stigmatization and exclusion of affected individuals}

In addition, the risk that a peanut-allergic child at a "peanut-free school" ("special school") will be stigmatized will remain. The ban on peanuts for all students could engender a greater lack of understanding on the part of unaffected children and increase the risk of psychological distress and exclusion for allergic children [1, 2].

\section{Misjudgment of high-risk situations}

The perception of supposed safety at a school designated to be "peanut-free" carries the risk for those affected that everyday situations both outside and inside the school are misjudged due to an altered risk assessment [3, 4]: "handing over responsibility to the school" can lead to greater anxiety in situations outside the school, especially when the affected child needs to fend for itself. It carries the risk of deprivation of the allergic child outside the school setting: no sports clubs (since these are not peanut-free), no children's choir, and, ultimately, stagnation in their development of social interaction, including the ability to take responsibility and develop self-respect for oneself.

A supposedly safe environment at school can also result in teachers no longer making appropriate risk assessments and, for example, teachers receiving no training in emergency management, or only inadequate training. But also on the part of the affected child, the fact that they are in a place deemed to be safe can result in them not having their emergency medication on them at all times.

\section{No reduction in severe reactions at schools in the USA with a peanut ban}

A retrospective study of public schools in the USA with and without peanut-restrictive policies showed that banning peanuts from being brought from home or offered in school, as well as peanut-free classrooms, do not affect the incidence of adrenaline administration at school [2]. Only the concept of making peanutfree tables available for affected children in school canteens emerged as beneficial; however, overall, only a small number of anaphylactic reactions were reported in schools without peanut-free tables. ${ }^{1}$ On the other hand, one must also consider the possible negative effects of such measures. For example, representatives of US patient organizations report that parents of peanut-allergic children are increasingly requesting physicians to issue certificates allowing their children to freely choose where they sit in the canteen, in order to avoid the social isolation of affected children due to peanut-free tables or an increased risk of confrontation with other children.

\section{Priority must be given to the support and protection of all pupils with food allergies}

Supporting and actively protecting at-risk pupils with chronic diseases, in this case (peanut) allergy, in their

\footnotetext{
1 The difference between schools with and without peanut-free tables was significant, but relates only to seven reactions in 196 schools without peanut-free tables and 19 reactions in 1875 schools with peanut-free tables (incidence rate per 10,000 students 0.6 versus $0.2 ; p=0.009$ ).
} 
everyday lives should be a priority [5]. The stringency of risk reduction measures can be adjusted to the sensitivity of the affected child. It is always advisable

- for all children to wash their hands before and after eating.

- when using food in lessons, e.g., when a class eats breakfast together, when cooking, or during handicrafts that materials are used that neither exclude children nor put them at risk of an allergic reaction.

In this context, one should also always consider those children who react to elicitors other than peanut. Although peanut is the most frequent elicitor of anaphylaxis in childhood, there are a number of other relevant triggers, such as milk, egg, and various edible nuts, that are relegated to the sidelines due to the focus on "peanuts", thereby depriving children affected by anaphylaxis elicitors other than peanut of due respect for their allergy $[6,7]$. Thus, the desire or demand to protect a group of pupils with severe allergic reactions (to peanut) would be at the expense of other pupils with similarly severe reactions to other allergens and negatively affect their disease management.

\section{Eliciting doses differ from individual to individual}

A major misconception created by the concept of "peanut-free schools" is the implication that even the tiniest quantities of the allergen need to be avoided in order to prevent hazardous reactions. However, this is not always the case. An international working group showed that less than $5 \%$ of all peanut-allergic children reacted to an eliciting dose of $1.5 \mathrm{mg}$ peanut protein (equivalent to around $6 \mathrm{mg}$ peanut $=$ around $1 / 200$ th of a peanut kernel) with objective symptoms [8]. All these reactions were mild.

According to a recent publication, in which children with equivocal peanut allergy underwent oral peanut challenge, a third ( $n=525)$ of 1634 challenged children with suspected peanut allergy $(78 \%)$ or precautionary avoidance of peanut without suspicion $(22 \%)$ reacted positively [9]. While $28 \%$ of the reactions were elicited by the administration of $25 \mathrm{mg}$ of peanut (equivalent to around $1 / 50$ th of a peanut kernel), $38 \%$ of the children only reacted after a dose of over $1 \mathrm{~g}$ of peanut (equivalent to a whole peanut). Only $10 \%(n=55)$ of the children that tested positive experienced an anaphylactic reaction, whereby the age of the tested child represented a risk factor, as well as the dose of peanut administered. For example, 13- to 18-year-olds had a three-fold higher risk for an anaphylactic reaction compared to 6- to 12-year-olds.

If one looks only at the anaphylactic reactions, there are children in whom even small doses of 25-100 mg peanut (around 1/50th to $1 / 10$ th of a peanut kernel) elicit anaphylaxis. This was the case in $9 \%$ of the mostly older individuals with peanut allergy. A good quarter $(27 \%)$ of children required a dose of between $200 \mathrm{mg}$ and $1 \mathrm{~g}$ peanut (around 1/6th of a whole peanut) to show anaphylactic symptoms. $40 \%$ only experienced an anaphylactic reaction after a dose of between 5 and $20 \mathrm{~g}$ peanut (approximately four to seven peanut kernels). These observations highlight the fact that the eliciting dose for severe reactions significantly differs from individual to individual and that very small doses are sufficient to elicit anaphylaxis in only a small number of peanut allergics.

\section{Fear of severe reactions through inadvertent exposure via inhalation and skin contact unfounded}

There are reports that the mere inhalation of peanut protein is sufficient to cause severe reactions or even anaphylaxis. However, this could not be demonstrated in targeted investigations [10-12]. It also does not appear that an allergy-relevant quantity of peanut protein capable of triggering severe symptoms can be airborne $[13,14]$. Fear of severe reactions due to skin contact with contaminated material or door handles is also unfounded. Contact of this kind can at most cause mild skin reactions $[15,16]$.

On the other hand, expecting an allergic reaction as a result of smelling or seeing peanuts can trigger a fear response that sometimes resembles an allergic reaction. Since fear responses are a potential differential diagnosis, it is possible to misjudge the risk status in both directions (incorrectly assessing an allergic reaction as a fear response and incorrectly assessing a fear response as an allergic reaction). These fears need to be combated through targeted education or patient information and, where necessary, an additional intervention in a medical environment (hospital/medical practice) during which the patient comes into contact with the allergen. A recently published study impressively showed that information on the minimal risk of allergic reactions due to mere skin contact as well as experiencing allergen contact significantly reduced anxiety in patients and their families and increased quality of life [12].

Although severe allergic reactions through inhalation or skin contact alone are unlikely, the use of a relevant allergen should be avoided in the classroom and other school environments in order to avoid causing even mild reactions and fostering anxieties. For example, it is advisable in cookery or baking clubs not to use ingredients to which a child in the class is allergic. In the case of peanut-allergic pupils, the authors recommend avoiding peanut flips, roasted peanuts, and whole peanuts in shells both in the classroom and at school events. 


\section{A reliable diagnosis as a basis for effective management strategies}

Above all, a reliable diagnosis is crucial for the appropriate management of a food allergy. The diagnosis should also facilitate an assessment of the eliciting dose and, ideally, be based on double-blinded placebo-controlled challenge testing. One must bear in mind that, also in peanut allergy, a natural tolerance can develop and re-evaluation at regular intervals is advisable [17]. This is important for all parties involved:

- For the parents, to enable them to better judge whether (and to what degree) their child is actually (still) allergic.

- For the physician, so that they can clearly identify patients with food allergy and make the diagnosis not only on the basis of elevated specific IgE.

- For pupils, so that the necessary measures can be based on a clear diagnosis.

\section{Sound risk assessment needs to be learned and practiced}

Optimal disease management includes a realistic assessment of hazardous situations. This needs to be learned and practiced-for each anaphylaxis trigger. In addition to information provided by the treating pediatrician and specialist dietician/nutritionist, AGATE (Arbeitsgemeinschaft Anaphylaxie - Training und Education e.V.) anaphylaxis training and education programs are suited to this end. These are offered by interdisciplinary teams at various locations in Germany (www.anaphylaxieschulung.de). Education programs are available not only for parents, but also for children, adolescents, teachers, and carers. The German Allergy and Asthma Association (Deutsche Allergie- und Asthmabund, DAAB) also offers advice, information, an e-learning program, and webinars on the subject for patients as well as teachers and carers. The aim of these measures is to establish optimal disease management for those affected and their families, recognize fears and concerns, and work to counteract these, thereby ensuring the best possible protection against allergic reactions in everyday life while achieving good integration in social structures.

\section{Conclusion}

The concept of "peanut-free schools" is not expedient for allergy sufferers and their parents and is potentially fraught with risk. What does make sense in the case of diagnosed food allergy is to implement appropriate measures in schools for allergen avoidance and emergency treatment for all food-allergic pupils, thereby enabling and ensuring pupils' safety and participation in classes and other school activities (Table 1). To this end, sufficient information, education,
Table 1 Fears and concerns of affected individuals when confronted with food allergens at school, and possible management strategies using peanut as an example

\begin{tabular}{|c|c|c|}
\hline \multicolumn{3}{|c|}{$\begin{array}{l}\text { School= dangerous? } \\
\text { What can the school with peanuts trigger in ...? }\end{array}$} \\
\hline $\begin{array}{l}\text { Pupils with peanut } \\
\text { allergy }\end{array}$ & $\begin{array}{l}\text { Parents of } \\
\text { peanut-aller- } \\
\text { gic children }\end{array}$ & Teachers \\
\hline Insecurity & $\begin{array}{l}\text { Fear of an aller- } \\
\text { gic reaction in } \\
\text { their child }\end{array}$ & $\begin{array}{l}\text { Fear of administering medica- } \\
\text { tion/doing something "wrong"/ } \\
\text { causing "harm" }\end{array}$ \\
\hline $\begin{array}{l}\text { Fear of supposed } \\
\text { peanut contact (in } \\
\text { school food, via } \\
\text { fellow students, in } \\
\text { the classroom) }\end{array}$ & $\begin{array}{l}\text { Fear that their } \\
\text { child will be } \\
\text { harassed by } \\
\text { teachers/fellow } \\
\text { students }\end{array}$ & $\begin{array}{l}\text { Fear of stressful situations due } \\
\text { to conflicts with parents and } \\
\text { students on the subject of: } \\
\text { "We'll bring to school and eat } \\
\text { what we want" }\end{array}$ \\
\hline $\begin{array}{l}\text { My parents are } \\
\text { scared for me }\end{array}$ & $\begin{array}{l}\text { Fear of being } \\
\text { "powerless" and } \\
\text { "unable to act" } \\
\text { due to not being } \\
\text { present }\end{array}$ & $\begin{array}{l}\text { Fear of liability in emergency } \\
\text { situations (duty of supervision, } \\
\text { liability for accidents, etc.) }\end{array}$ \\
\hline $\begin{array}{l}\text { Lack of understand- } \\
\text { ing from teachers/ } \\
\text { fellow students, fear } \\
\text { of exclusion and } \\
\text { bullying }\end{array}$ & $\begin{array}{l}\text { Highly "protec- } \\
\text { tive" behavior }\end{array}$ & $\begin{array}{l}\text { Fear of outings/excursions, } \\
\text { activities such as cookery } \\
\text { classes, etc. }\end{array}$ \\
\hline
\end{tabular}

What are the possible management strategies?

School as a place for all to learn together and inclusively for life

Accepting the food allergy and learning to live with it

Getting background information on food allergies per se, thereby learning to identify misinformation, e.g., "inhaling peanut causes death from anaphylaxis."

Formulate local preventive strategies (e.g., avoiding allergy elicitors when cooking and baking together, voluntary avoidance of, e.g., peanut flips at celebrations and on school trips)

Training to recognize and deal with emergency situations

Respectful dialog and exchange on "being there for one another"

Strengthening at- Making infor- Creating the framework conditentiveness and mation on their tions to care for children with (physical) self-aware- child's disease food allergies and anaphylaxis ness available risk, learning together

Self-management Learning to let go Supporting and strengthening the child in their development/ self-management

Assuming responsi- Learning to trust Learning to make sound, parbility for oneself and their child ticipative decisions (shared gaining self-respect decision-making) using the food allergy as an example

Learning: to be there for one another

and training on anaphylaxis and its everyday management, as provided by reliable sources, are required.

Funding Open Access funding provided by Projekt DEAL.

Conflict of interest B. Ahrens and V. Mahler state that the content and opinions expressed in this position paper reflect the personal expert opinions of the authors and should not be interpreted or cited as if they had been made on behalf of the relevant higher national federal authorities, the European Medicines Agency, or one of its committees or working groups, or reflects their position. K. Beyer declares having received grants and honoraria from Aimmune, DBV, Infectopharm, and Mylan, outside the present work. K. Blümchen declares having received grants and/or hon- 
oraria from Novartis, HAL Allergy, ThermoFisher, Bencard Allergie, Allergopharma, ALK, DBV technologies, Aimmune Therapeutics, Nestle, and Nutricia, outside the present work. A. Heratizadeh declares having received honoraria from LEO Pharma, Novartis, Pierre Fabre, Sanofi-Genzyme, Beiersdorf, Hans Karrer, Nutricia, Meda, and Lilly, as well as grants from Janssen, outside the present work. S. Lau declares having received honoraria from DBV, Sanofi-Aventis, Allergopharma, and ALK, outside the present work. M. Worm declares having received advisory board and lecture honoraria from Allergopharma GmbH \& Co. KG, ALK-Abelló Arzneimittel GmbH, Mylan Germany GmbH, Leo Pharma GmbH, Sanofi-Aventis Deutschland $\mathrm{GmbH}$, Regeneron Pharmaceuticals, DBV Technologies S.A, Stallergenes GmbH, HAL Allergie GmbH, Bencard Allergie GmbH, Aimmune Therapeutics UK Limited, Actelion Pharmaceuticals Deutschland GmbH, Novartis AG, Biotest AG, AbbVie Deutschland GmbH \& Co. KG, and Lilly Deutschland $\mathrm{GmbH}$, outside the present work. B. BallmerWeber reports personal fees from ThermoFisher Scientific, personal fees from Stallergenes, personal fees from Novartis, outside the submitted work. I. Reese, S. Doelle-Birke, J. KleineTebbe, L. Lange, U. Lepp, C. Schäfer, S. Schnadt, Z. Szepfalusi, A. Wassmann-Otto and T. Werfel declare that they have no competing interests.

Open Access This article is licensed under a Creative Commons Attribution 4.0 International License, which permits use, sharing, adaptation, distribution and reproduction in any medium or format, as long as you give appropriate credit to the original author(s) and the source, provide a link to the Creative Commons licence, and indicate if changes were made. The images or other third party material in this article are included in the article's Creative Commons licence, unless indicated otherwise in a credit line to the material. If material is not included in the article's Creative Commons licence and your intended use is not permitted by statutory regulation or exceeds the permitted use, you will need to obtain permission directly from the copyright holder. To view a copy of this licence, visit http://creativecommons.org/licenses/by/4.0/.

\section{References}

1. Fong AT, Katelaris CH, Wainstein BK. Bullying in Australian children and adolescents with food allergies. Pediatr Allergy Immunol. 2018;29:740-6.

2. Bartnikas LM, Huffaker MF, Sheehan WJ, Kanchongkittiphon W, Petty CR, Leibowitz R, et al. Impact of school peanut-free policies on epinephrine administration. J Allergy Clin Immunol. 2017;140:465-73.

3. StensgaardA, DunnGalvinA, NielsenD, MunchM,BindslevJensen C. Green, Yellow, and Red riskperception in everyday life-a communication tool. Allergy. 2017;72:1114-22.

4. Monks H, Gowland MH, MacKenzie H, Erlewyn-Lajeunesse M, King R, Lucas JS, et al. How do teenagers manage their food allergies? Clin Exp Allergy. 2010;40:1533-40.

5. Rogers A, Vassilev I, Sanders C, Kirk S, Chew-Graham C, KennedyA, et al. Social networks, work and network-based resources for the management of long-term conditions: a framework and study protocol for developing self-care support. Implement Sci. 2011;6:56.

6. Osterlund J, Winberg A, West CE. A 10-year review found increasing incidence trends of emergency egg allergy re- actions and food-induced anaphylaxis in children. Acta Paediatr. 2019;108:314-20.

7. Grabenhenrich LB, Dolle S, Moneret-Vautrin A, Kohli A, Lange L, Spindler T, et al. Anaphylaxis in children and adolescents: the European Anaphylaxis Registry. J Allergy Clin Immunol. 2016;137:1128-1137.e1.

8. Hourihane JO, Allen KJ, Shreffler WG, Dunngalvin G, Nordlee JA, Zurzolo GA, et al. Peanut Allergen Threshold Study (PATS): Novel single-dose oral food challenge study to validate eliciting doses in children with peanut allergy. JAllergy Clin Immunol. 2017;139:1583-90.

9. Arkwright PD, MacMahon J, Koplin J, Rajput S, Cross S, Fitzsimons R, et al. Severity and threshold of peanut reactivity during hospital-based open oral food challenges: an international multicenter survey. Pediatr Allergy Immunol. 2018;29:754-61.

10. Leonardi S, Pecoraro R, Filippelli M, Miraglia del Giudice M, Marseglia G, Salpietro C, et al. Allergic reactions to foods by inhalation in children. allergy asthma proc. 2014;35:288-94.

11. James JM, Crespo JF. Allergic reactions to foods by inhalation. Curr Allergy Asthma Rep. 2007;7:167-74.

12. Weinberger T, Annunziato R, Riklin E, Shemesh E, Sicherer SH. A randomized controlled trial to reduce food allergy anxiety about casual exposure by holding the allergen: TOUCH study. J Allergy Clin Immunol Pract. 2019;7:2039-2042.el.

13. Perry TT, Conover-Walker MK, Pomes A, Chapman MD, Wood RA. Distribution of peanut allergen in the environment. JAllergy Clin Immunol. 2004;113:973-6.

14. Brough HA, Makinson K, Penagos M, Maleki SJ, Cheng H, Douiri A, et al. Distribution of peanut protein in the home environment. JAllergy Clin Immunol. 2013;132:623-9.

15. Wainstein BK, Kashef S, Ziegler M, Jelley D, Ziegler JB. Frequency and significance of immediate contact reactions to peanut in peanut-sensitive children. Clin Exp Allergy. 2007;37:839-45.

16. SimonteSJ, Ma S, Mofidi S, Sicherer SH. Relevance of casual contact with peanut butter in children with peanut allergy. JAllergy Clin Immunol. 2003;112:180-2.

17. Worm M, Reese I, Ballmer-Weber B, Beyer K, Bischoff SC, Classen M, et al. Guidelines on the management of IgEmediated food allergies: S2k-Guidelines of the German Society for Allergology and Clinical Immunology (DGAKI) in collaboration with the German Medical Association of Allergologists (AeDA), the German ProfessionalAssociation of Pediatricians (BVKJ), the German Allergy and Asthma Association (DAAB), German Dermatological Society (DDG), the German Society for Nutrition (DGE), the German Society for Gastroenterology, Digestive and Metabolic Diseases (DGVS), the German Society for Oto-Rhino-Laryngology, Head and Neck Surgery, the German Society for Pediatric and Adolescent Medicine (DGKJ), the German Society for Pediatric Allergology and Environmental Medicine (GPA), the German Society for Pneumology (DGP), the German Society for Pediatric Gastroenterology and Nutrition (GPGE), German Contact Allergy Group (DKG), the Austrian Society for Allergology and Immunology (AE-GAI), German Professional Association of Nutritional Sciences (VDOE) and the Association of the Scientific Medical Societies Germany (AWMF). Allergo J Int. 2015;24:256-93. 